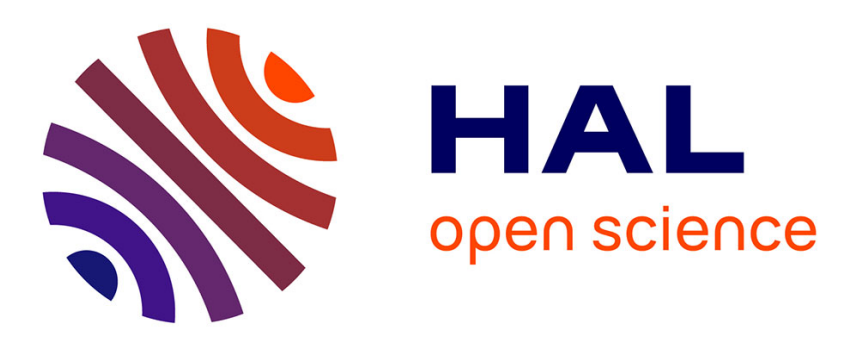

\title{
Cyclization Dynamics and Competitive Processes of Photochromic Perfluorocyclopentene Dithienylethylene in Solution
}

\author{
Ismail Hamdi, Guy Buntinx, Amit Kumar Tiwari, Stéphanie Delbaere, \\ Michinori Takeshita, Stéphane Aloïse
}

\section{To cite this version:}

Ismail Hamdi, Guy Buntinx, Amit Kumar Tiwari, Stéphanie Delbaere, Michinori Takeshita, et al.. Cyclization Dynamics and Competitive Processes of Photochromic Perfluorocyclopentene Dithienylethylene in Solution. ChemPhysChem, 2020, 21 (19), pp.2223-2229. 10.1002/cphc.202000516 . hal03292762

\section{HAL Id: hal-03292762 \\ https://hal.science/hal-03292762}

Submitted on 20 Jul 2021

HAL is a multi-disciplinary open access archive for the deposit and dissemination of scientific research documents, whether they are published or not. The documents may come from teaching and research institutions in France or abroad, or from public or private research centers.
L'archive ouverte pluridisciplinaire HAL, est destinée au dépôt et à la diffusion de documents scientifiques de niveau recherche, publiés ou non, émanant des établissements d'enseignement et de recherche français ou étrangers, des laboratoires publics ou privés. 


\title{
Cyclization Dynamics and competitive processes of photochromic perfluorocyclopentene dithienylethylene in solution.
}

\author{
Ismail Hamdi, ${ }^{[a]}$ Guy Buntinx, ${ }^{[a]}$ Amit Kumar Tiwari, ${ }^{[a, b]}$ Stéphanie Delbaere, ${ }^{[a]}$ Michinori Takeshita, ${ }^{[c]}$ and \\ Stéphane Aloïse* [a]
}

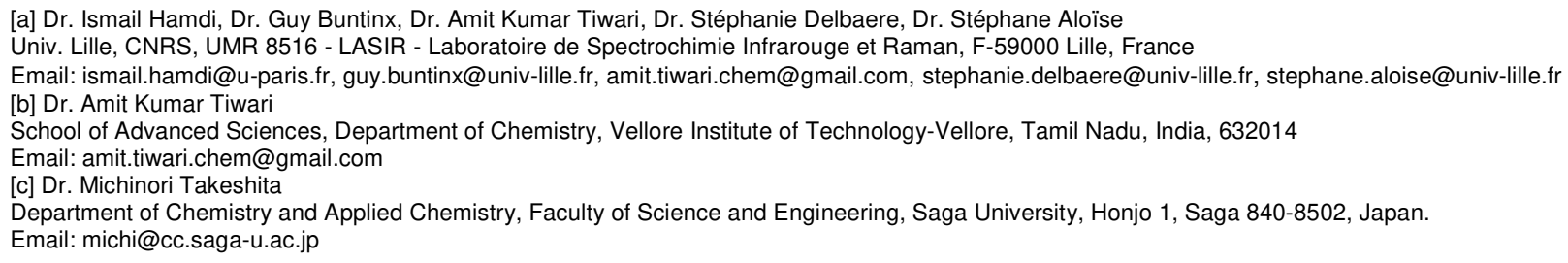

Abstract: Time-resolved absorption spectroscopy measurements were applied to study the dynamics of photochromic 1,2-Bis(2,4dimethylthiophene-3-yl)perfluoro-cyclopentene (DMTPF) in chloroform including antiparallel conformer ring-closure reaction and parallel conformer photophysics. All characteristic times are given, discussed and compared to a previous publication concerning the close molecule substituted with phenyl rings. (Hamdi et al, pccp, 2016). Apart from the expected photocyclization process, a ring condensed by-product formation is observed and hypothesis concerning the origin of this by-product are presented.

\section{Introduction}

Designing of the photochromic materials which convert reversibly its color upon light stimulation ${ }^{1-4}$ have gained the attraction of material scientist due to its various applications in holography, ${ }^{5}$ information storage/processing, ${ }^{6}$ biosensors, ${ }^{7,8}$ fluorescent probe, ${ }^{9,10}$ smart materials ${ }^{11,12}$ etc. Among the different molecular switches necessary to elaborate such applications, ${ }^{1-4}$ diarylethenes (DAEs) and more specifically dithienylethenes (DTEs) $^{13,14}$ are often used due to their good photochromic properties especially in terms of fatigue resistance. ${ }^{15}$ DTEs in solution are having property to undergo efficient photocyclization $\left(\phi_{\text {cycl }} \sim 0.2-0.5\right)$ between uncolored open form (OF) and colored closed form (CF) in presence of UV light, whereas photoreversion reactions are known to be less efficient $\left(\phi_{r e v} \sim 0.01\right)$ when expose towards the visible light. ${ }^{13,14}$ During the last decades, the quantum yield of carbon-carbon photoelectrocyclization limited to 0.5 was a subject of interest explained in term of coexistence of two OF isomers having parallel $(\mathrm{P})$ and anti-parallel (AP) conformations in equal proportions but only the latter being photoactive. ${ }^{16,17}$ To overpass such limitation some researchers focused their efforts on exploring purposed-designed synthetic approach ${ }^{18-21}$ or specific excited-state reactivity. ${ }^{22,23}$ Indeed, the rationalization of complex excited state mechanisms are highly desired to still improve photochromic performances and so considerable investigations have been devoted worldwide to explore the excited state topologies of DTEs (or DAEs) via advanced optical

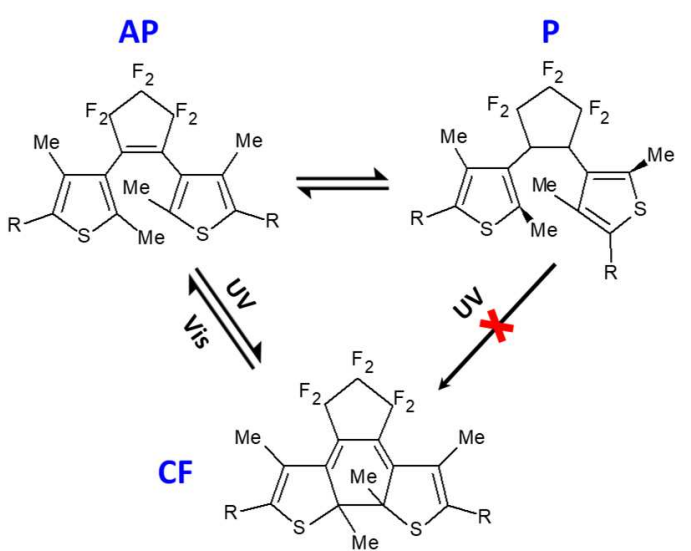

Scheme 1. UV/Vis Photochromic reactions of DMTPF $(R=H)$ and DTE $\left(\mathrm{R}=\mathrm{C}_{6} \mathrm{H}_{5}\right)$ between the OF and CF. Thermal Interconversion between AP and $\mathrm{P}$ conformers is indicated.

spectroscopies ${ }^{24-27}$ and/or computational chemistry. ${ }^{28-30}$ In this perspective, our group has actively investigated the spectrokinetic features on the series of bridged DAEs, ${ }^{31}$ bridged DTEs ${ }^{29,32,33}$ or DTEs dedicated to supramolecular chemistry ${ }^{34}$ using ultrafast spectroscopies combined with (TD)-DFT calculations. Our leitmotiv was the attempt to detangle the photochemistry of the antiparallel (AP) conformers from the photophysics of parallel (P) conformers by comparing bridged/constrained vs free analog molecules (the initial purpose of the former being the blockade of the molecule into a photoactive conformation). Due to its commercial availability, normal dithienylethene 1,2-bis(2,4dimethyl-5-phenyl-3-thienyl) perfluorocyclopentene (denoted as 
DTE, hereafter) has become a photoswitch of reference, ${ }^{26,35-38}$ reason why we reinvestigated its photochemistry together with a series of polyether bridged analogs. The main outcomes ${ }^{32}$ were pointed as follow: (i) for the $\mathrm{P}^{*}$ conformer, an Intersystem crossing (ISC) occurred (40-150 ps) to produce a first triplet state $\left({ }^{3} \mathrm{P}\right)$ after ultrafast relaxation toward $S_{1}$ relaxed state. Later on the ${ }^{3} \mathrm{P}$ state relaxed within few tens of $\mu$ s to the ground state; (ii) for the $A P^{*}$ conformer, the photocyclization reaction occur immediately after light absorption (100-200 fs) starting from the Franck-Condon (FC) region while the relaxed singlet state is populated in parallel way and evolves through an ISC reaction (1-40 ps) and generate a second triplet state, ${ }^{3} \mathrm{AP}$ with a lifetime depending on the structural constraints; (iii) interconversion between the two triplet states has been experimentally identified, e.g. ${ }^{3} \mathrm{AP} \leftrightarrow{ }^{3} \mathrm{P}$ only for some polyether bridged DTE $\left(\mathrm{DTE}^{-\mathrm{O}_{6}}\right.$ in ref ${ }^{33}$ ); (iv) an unidentified species (denoted as " $X$ " hereafter) have been reported with variable statistical weight $(0-50 \%)$ along with the two triplet states within $\mu$ s regime.

In this paper, we decided to reinvestigate a smaller structural analogue of DTE without the two terminal phenyl groups, the 1,2bis(2,5-dimethyl-3-thienyl)-perfluorocyclopentene noticed in the following DMTPF. Such molecule has been studied in the past in crystalline phase ${ }^{35,36}$ and in solution ${ }^{37,38}$ with the main features to present a photocyclization more efficient in crystalline phase $\left(\phi_{\text {cycl }}=0.5\right)$ as compared to hexane solution $\left(\phi_{\text {cycl }}=0.21\right)$ while photoreversion yields are almost identical $\left(\phi_{\text {cycl }}=0.12\right)$ in both phases. Knowing that AP population was restricted to $17 \%$ in the solid state (compared to almost $50 \%$ in solution), the authors concluded for an excited state energy migration during photoconversion, the $\mathrm{P}$ conformer acting as a sensitizer.

So, focalizing our attention on photocyclization process, we have applied transient absorption spectroscopy on the microfemtosecond timescale in order to elucidate the excited states dynamics of DMTPF in solution with a systematic comparison with the previous study dealing with DTE molecule. We will pay attention on the possible existence of triplet or $X$ species and discuss the previous results found in the literature under the light on our new results.

\section{Results and Discussion}

\subsection{General photochemical features in solution.}

The photochromism of DMTPF in chloroform is illustrated in Figure 1a through absorption spectra under continuous UV irradiation for less than $10 \mathrm{~min}$. For uncoloured solution, OF has a peak at $\sim 235 \mathrm{~nm}$. Upon UV irradiation with $302 \mathrm{~nm}$ light, the solution becomes pink and the spectrum

\begin{tabular}{|c|c|c|c|c|c|}
\cline { 5 - 6 } \multicolumn{1}{c|}{} & \multicolumn{2}{|c|}{$\lambda_{\mathrm{abs}}^{\max }(\mathbf{n m})$} & \multirow{2}{*}{ Population } & \multicolumn{2}{c|}{ Quantum yields } \\
\cline { 2 - 3 } \cline { 5 - 6 } \multicolumn{1}{c|}{} & OF & CF & \% (P:AP) & Cyclization & Triplet \\
\hline DMTPF & 235 & 535 & $80: 20$ & 0.22 & 0.75 \\
\hline DTE & 273 & 575 & $52: 48$ & 0.46 & 0.4 \\
\hline
\end{tabular}

Table 1. Experimental photochromic parameters of DMTPF and DTE $\left(\right.$ ref $\left.^{32}\right)$ in chloroform.
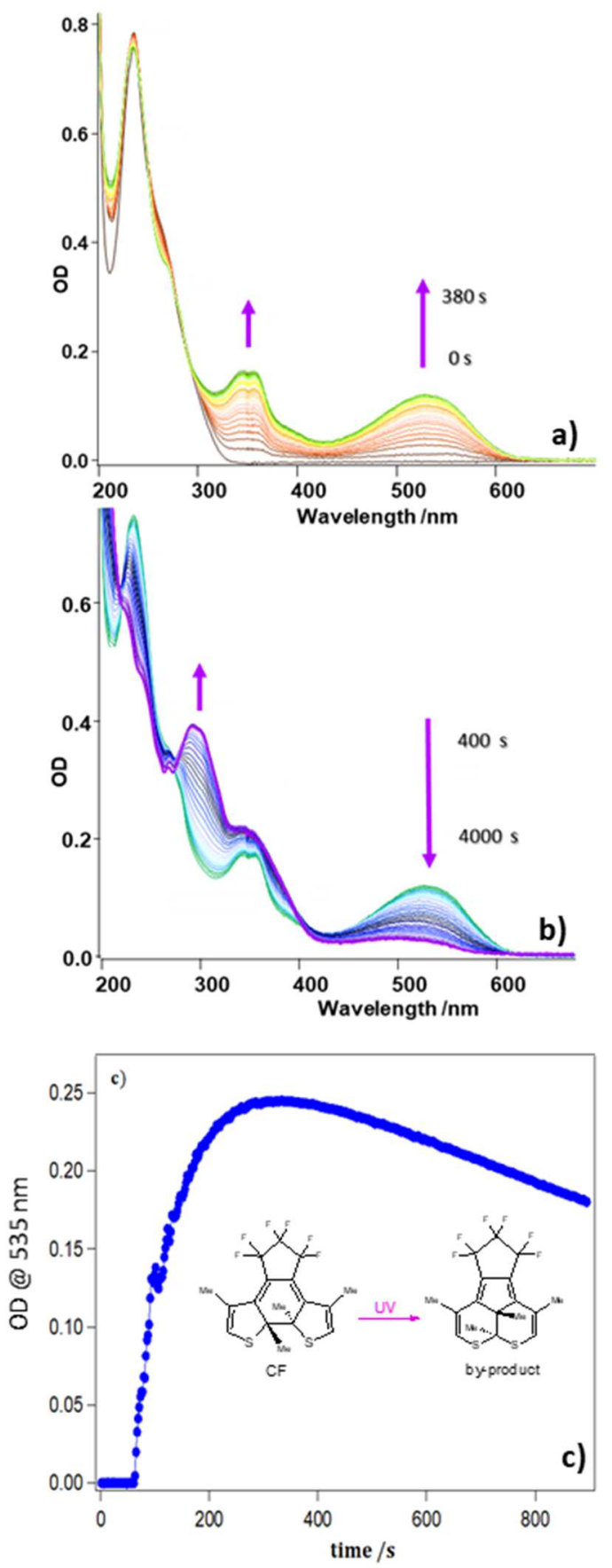

Figure 1. (a) Absorption spectral change of DMTPF in chloroform $(50 \mu \mathrm{M})$ upon UV irradiation (302 nm) up to 10 minutes and (b) up to 1 hour (c) Absorbance evolution @ $532 \mathrm{~nm}$ with time for an UV irradiation starting at 60 s after the beginning of the recording. 
dramatically changes and has a peak at $351 \mathrm{~nm}$ and broad absorption band at $535 \mathrm{~nm}$ corresponding to the absorption of CF. After $350 \mathrm{~s}$ irradiation time with continuous UV, the absorbance of CF does not increase further and a plateau is reached (see Figure 1b) which indicates the photo-stationary state (PSS). However, with further UV irradiation, the solution turns to pale yellow and as seen in Figure 1c, a new band appears at $\sim 300 \mathrm{~nm}$ with a concomitant decrease of the band at $532 \mathrm{~nm}$ responsible for the decrease of the curve in Figure $1 b$ after PSS plateau. In contrast, as seen in Figure S.1, the PPS plateau for DTE is very stable (more than 50 hours) evidencing the lack of any photodegradation. In the case of DMTPF, by analogy with previous work dealing on neighbouring molecules, ${ }^{39,40}$ such drastic spectral modifications are probably due to the well-known condensed rings by-product formation resulting from UV excitation of the CF (see inset of Figure 1c). Such by-product species is well characterized by the band around $300 \mathrm{~nm}$ and the vanishing contribution in the visible region. This result indicates that the presence of the phenyl groups drastically increases the stability of the CF of DTE compared to DMTPF. Note that for the time-resolved studies here below, we have chosen experimental conditions in order to neglect as much as possible the by-product contamination.

Some important photochemical parameters were measured in chloroform and gathered in Table 1. The P:AP ratio for DMTPF has been determined based on ${ }^{1} \mathrm{H}-\mathrm{NMR}$ measurements to be $80: 20$ at ambient temperature in d-chloroform (Figure S.2). For DTE, we have recover the same $52: 48$ ratio that was previously reported by Irie and co-workers. ${ }^{37}$

The main indicative results concern the proportion of $P$ conformers from $52 \%$ for DTE to $80 \%$ for DMTPF. It immediately rationalizes the quantum yields of the cyclization for DMTPF (0.22) being more than 2 times lower compared to DTE $(0.46)$ paralleling the decrease of AP population from 48 to $20 \%$. Another important findings concerns the triplet quantum yields measured by the method of energy transfer with beta-carotene we already applied to DTE ${ }^{32}$ indicated in the table 1. For DMTPF this value is as high as 0.75 while for DTE, it decreases down to 0.4. Actually, it is tempting to correlate the high triplet formation efficiency with the high proportion of parallel conformer. Indeed, a quantitative estimation for the intrinsic cyclization yield gives almost an unit value $(\approx 0.22 / 0.2)$ indicating that almost all photoexcited $\mathrm{AP}$ is converted to $\mathrm{CF}$ with no population accumulated in the triplet state ${ }^{3} \mathrm{AP}$. First, such efficient mechanism is consistent with a ring closing process from the Franck-Condon region in proximity with conical intersection for which competitive routes are not taken. Then, the apparent

\begin{tabular}{ccccc}
\hline & $\boldsymbol{\tau}_{\mathbf{1}}$ & $\boldsymbol{\tau}_{\mathbf{2}}$ & $\boldsymbol{\tau}_{\mathbf{3}}$ & $\boldsymbol{\tau}_{\mathbf{4}}$ \\
\hline DMTPF & $0.09(1)$ & $0.30(4)$ & $1.2(6)$ & $80(1)$ \\
DTE $^{32}$ & $0.10(2)$ & $0.20(5)$ & $1.0(2)$ & $55(8)$ \\
\hline
\end{tabular}

Table 2. Characteristic times (in ps) deduced from the global fitting method applied to femtosecond transient absorption data for DMTPF and DTE.

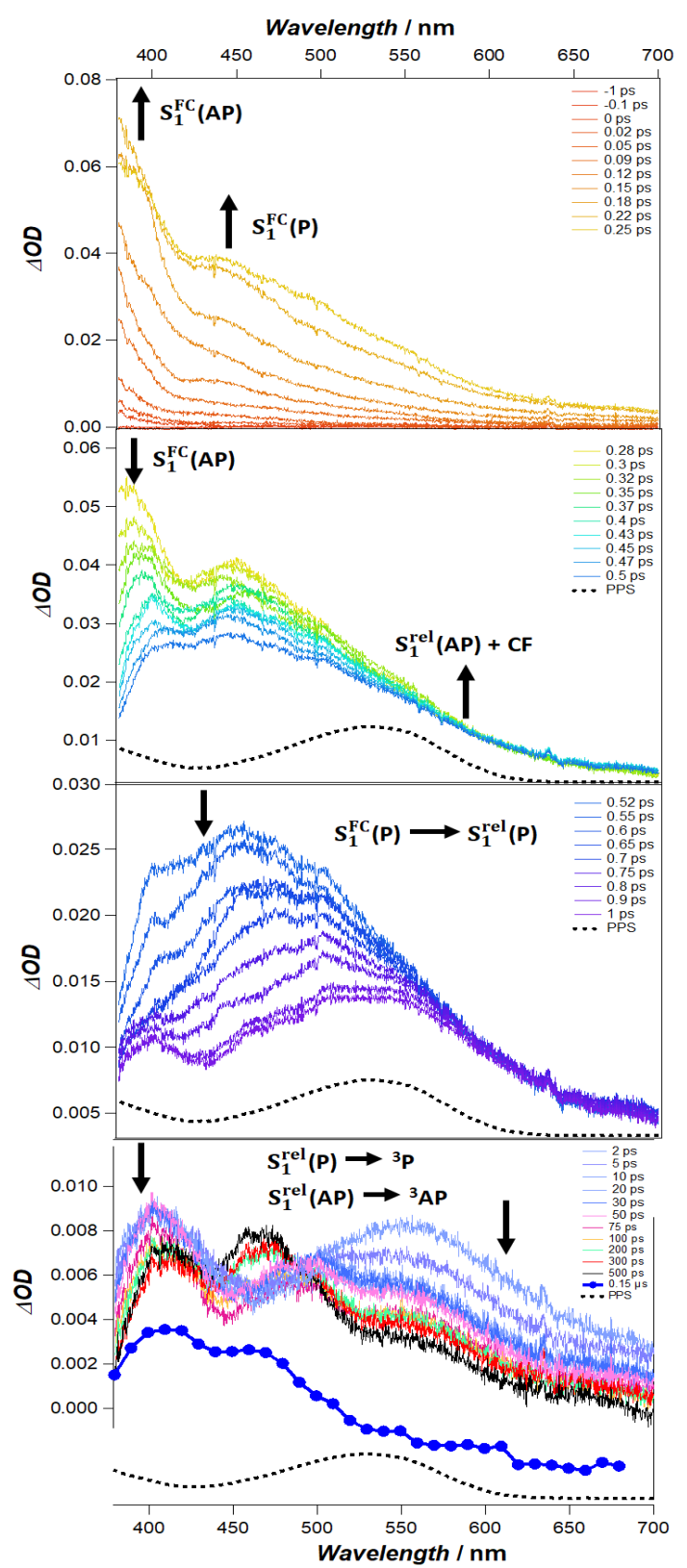

Figure 2. Femto-picosecond time-resolved absorption spectra of DMTPF in chloroform $\left(2-10^{-4} \mathrm{M}\right)$ using $320 \mathrm{~nm}$ excitation wavelength. Transient data are separated into 4 different temporal windows for improved clarity. All spectra are corrected from the GVD. The assignments of the different bands are indicated (see text).

discrepancy between the high intrinsic cyclization yield and high triplet formation yield can be explained in term of ${ }^{1} \mathrm{AP}$ species 
mainly produced through ${ }^{1} \mathrm{P}$ species upon rapid interconversion. Computational estimation of the potential barrier between ${ }^{1} \mathrm{AP}$ and ${ }^{1} \mathrm{P}$ will be published elsewhere. By the way, we will discuss this point below with the aid of transient spectroscopy. Indeed, in the following we will describe the ultrafast dynamics of this molecule knowing that the photocyclization mechanism and the competitive process ( $P$ photophysics) are very similar to DTE molecule. For that reason, we will keep the same notations compare to our first article (we also present the results in a short manner) but we will present the transient species following the natural deexcitation timescale, femtosecond/picosecond regime and then nanosecond regime for which the two molecules display some different features.

\subsection{Excited States dynamics in the pico-femtosecond regime.}

The early photophysics just after laser excitation is now investigated. Figure 2 shows time-resolved transient absorption spectra obtained after the excitation of the DMTPF OF (for DTE, see Figure 6 of ref $^{32}$ ) in chloroform solution with a femtosecond $320 \mathrm{~nm}$ laser pulse, recorded in the $380-700 \mathrm{~nm}$ spectral range within four temporal windows $(-1-0.25,0.28-0.5,0.52-1$ and 2-500 ps). Global fitting of transient signal with four-exponential functions, convoluted with a Gaussian profile simulating the pump-probe correlation function are shown in supporting information (see Figure S.3). The characteristic times for DMTPF compared to DTE are represented in Table 3. As already said, because of similar results, the interpretations made for DMTPF data of will stick those made for DTE molecule in our previous work. The transient data results are summarized on Figure 4.

For short delay times (-1-0.25 ps), just after laser excitation, the spectra present essentially two intense bands peaking at $385 \mathrm{~nm}$ and $450 \mathrm{~nm}$, respectively. By analogy with our previous work, these bands are attributed to the excited state absorption (ESA) of $S_{1}$ states on the Franck-Condon region (FC) for both $\mathrm{AP}$ and $\mathrm{P}$ conformers, i.e. $\mathrm{S}_{1}^{\mathrm{FC}}(\mathrm{AP})$ and $\mathrm{S}_{1}^{\mathrm{FC}}(\mathrm{P})$. For the delay times between $0.28-0.5 \mathrm{ps}$ on the second panel, we observed a decrease of the band peaking at $385 \mathrm{~nm}$ while, in the same time, the $550-750 \mathrm{~nm}$ edge is maintained constant. Indeed, in this spectral range, the vanishing signal is compensated in the same extent by a rising component which matches perfectly the $\mathrm{CF}$ visible band. The related characteristic time can thus be ascribed to the photocyclization of DMTPF $(\mathrm{OF} \rightarrow \mathrm{CF})$ which takes place with a time constant of $90 \mathrm{fs}$. For the third panel (0.52-1 ps), the ESA peaking at $450 \mathrm{~nm}$ decreases with a characteristic time of $300 \mathrm{fs}$. This evolution is attributed to the relaxation of the FC region for $\mathrm{P}$ conformer $\left(\left(\mathrm{S}_{1}^{\mathrm{FC}}(\mathrm{P}) \rightarrow \mathrm{S}_{1}^{\text {rel }}(\mathrm{P})\right)\right.$. Note that this spectral
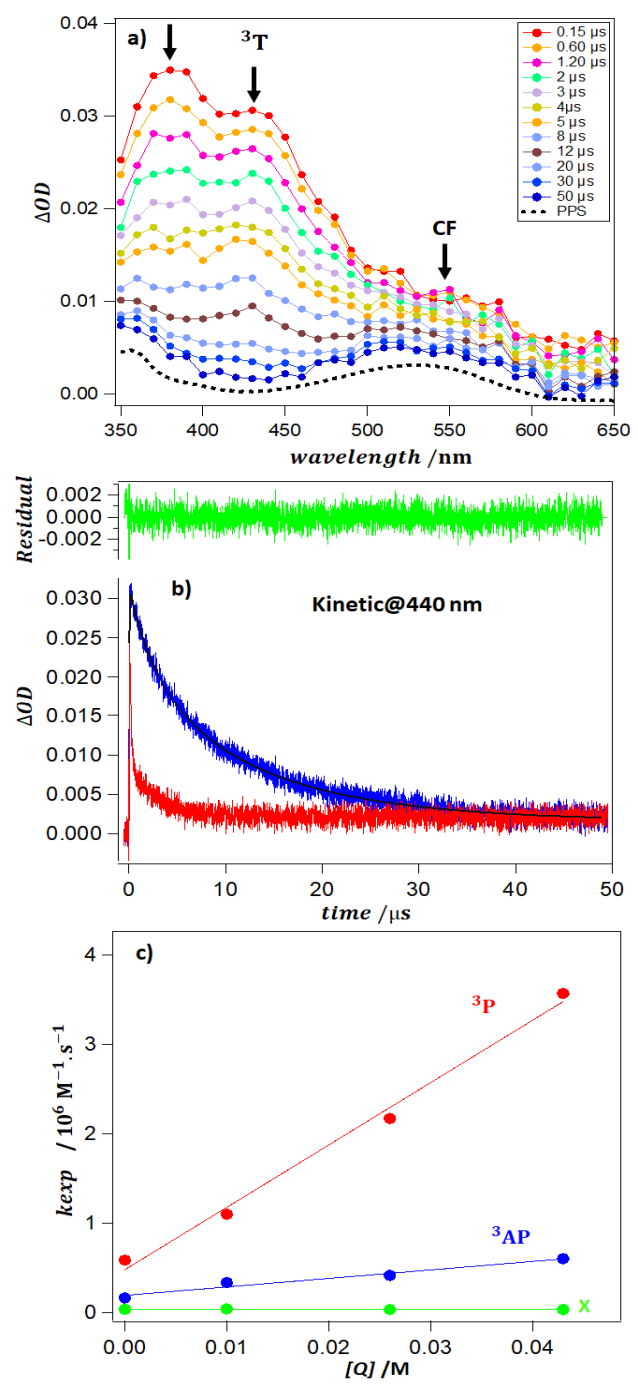

Figure 3. (a) Transient absorption spectra of DMTPF in chloroform $\left(510^{-4} \mathrm{M}\right)$ for different time delays after nanosecond laser excitation at $290 \mathrm{~nm}$ and (b) Kinetic traces measured at $440 \mathrm{~nm}$ for solutions initially saturated with $\mathrm{N}_{2}$ gas (blue line) or $\mathrm{O}_{2}$ gas (red line). (c) Stern-Volmer plots concerning experimental decays $k_{\text {exp }}$ of two triplet states and $\mathrm{X}$ species obtained from kinetics at $440 \mathrm{~nm}$ vs diene quencher concentration $[\mathrm{Q}]$.

evolution was more difficult to detect for DTE, and can be related to the higher percent of $\mathrm{P}$ conformer population for DMTPF than for DTE ( $80 \%$ vs $52 \%)$. Finally, for pump-probe delay times higher than 2 ps, we observed a decrease of both transient signals with two different characteristic times 1.2 ps and 80 ps respectively attributed to the intersystem-crossing (ISC) of the AP conformer $\left(\mathrm{S}_{1}^{\text {rel }}(\mathrm{AP}) \rightarrow{ }^{3} \mathrm{AP}\right)$, and $\mathrm{P}$ conformer $\left(\mathrm{S}_{1}^{\text {rel }}(\mathrm{P}) \rightarrow{ }^{3} \mathrm{P}\right)$. Interestingly, the effect of introducing phenyl groups into the photochromic core does not affect the ISC of the AP species (1.2 ps vs $1.0 \mathrm{ps}$ ) contrary to the $P$ species. This effect of structure can be nicely rationalized in terms of unpaired electrons well localized on the 


\begin{tabular}{|c|c|c|c|c|c|}
\hline & $\tau_{1}\left({ }^{3} \mathrm{P}\right)$ & $\tau_{2}\left({ }^{3} \mathrm{AP}\right)$ & $\tau_{3}(\mathrm{X})$ & $k_{1}^{Q}$ & $k_{2}^{Q}$ \\
\hline$\overline{\text { DMTPF }}$ & $\begin{array}{l}1.80(6) \\
(35 \%)\end{array}$ & $\begin{array}{l}4(1) \\
(15 \%)\end{array}$ & $\begin{array}{l}13(1) \\
(50 \%)\end{array}$ & $0.09(2)$ & $0.70(5)$ \\
\hline DTE & $\begin{array}{c}2.60(3) \\
(80 \%)\end{array}$ & $\begin{array}{r}25.5(4) \\
(20 \%)\end{array}$ & $\ldots$ & $0.10(4)$ & $2.23(1)$ \\
\hline
\end{tabular}

Table 3. Lifetimes (in $\mu \mathrm{s}$ ) deduced from multi-exponential fitting of transient kinetics obtained from the laser-flash photolysis experiment (the relative contributions are given into parenthesis) for DMTPF and DTE (ref ${ }^{32}$ ). Quenching rate constants $\left(10^{8} \mathrm{M}^{-1} \mathrm{~s}^{-1}\right)$ of $\mathrm{AP}, \mathrm{P}$ and $\mathrm{CF}$ species are also indicated (see text).

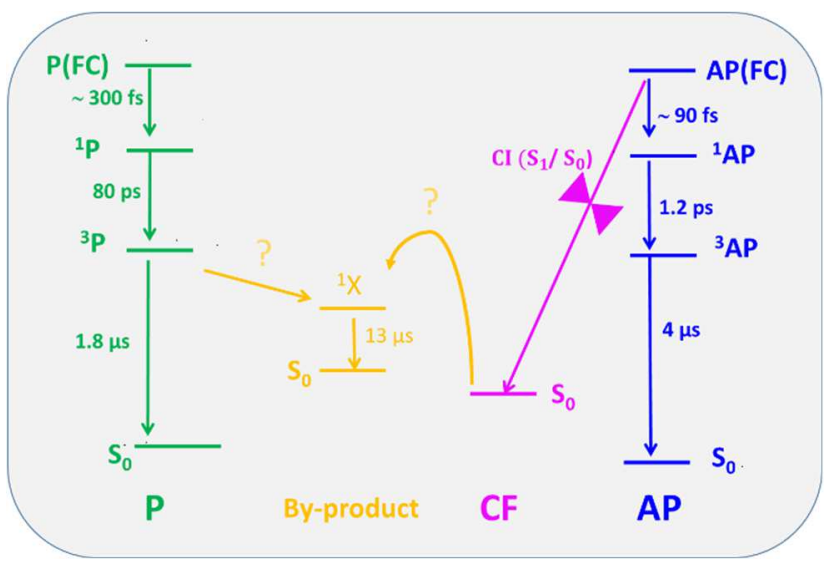

Figure 4. Photochemical processes (illustrations) including characteristic times derived according transient spectroscopy.

reactive carbons suggesting also a possible steric effect for the parallel species. Indeed, the faster ISC for DTE P conformer ( $55 \mathrm{ps}$ instead of $80 \mathrm{ps}$ ) has to be related with torsional effect induced by the phenyl groups.

In summary, the ultrafast photocyclization from the FC region gives birth to the $\mathrm{CF}$ is in competition with the ISC of both $\mathrm{AP}$ and $\mathrm{P}$ conformers. The deactivation pathways of both triplet states are now under examination.

\subsection{Excited state dynamics in the nano-microsecond regime.}

Two triplet states. The transient absorption spectra of the OF of DMTPF in chloroform excited at $290 \mathrm{~nm}$ and recorded in the $350-650 \mathrm{~nm}$ spectral range within a time windows of 0.15-50 $\mu \mathrm{s}$ are shown in Figure 3a. The spectra present essentially three bands: two intense bands peaking near $380-390 \mathrm{~nm}$ and $440 \mathrm{~nm}$ and a low intensity band at $\sim 540 \mathrm{~nm}$. In the $0.15-50 \mu \mathrm{s}$ time domain, spectral evolution shows a subsequent decrease of the red bands letting appear the CF spectra (see PPS spectra in black dashed curved). Those transient data have to be compared with DTE case previously reported (see Figure 2 in ref $^{32}$ ).
As seen in Figure 3b, the differential absorption kinetic curve recorded at $440 \mathrm{~nm}$ (blue color curve) is well-fitted with a gaussian convoluted tri-exponential function (to take into account the irf) with decay time constants of $1.8 \mu \mathrm{s}(35 \%), 4 \mu \mathrm{s}$ $(15 \%)$ and $13 \mu \mathrm{s}(50 \%)$. Note that, these values are lower than those reported for DTE molecule $(2.55 \mu \mathrm{s}$ and $25.5 \mu \mathrm{s})$. After addition of oxygen in the solution, those three times are totally quenched (see red curve in the same figure) which suggests that transient species are either biradicals or triplet states. According to our previous work published for DTE, ${ }^{32}$ we attributed $\tau_{1}$ and $\tau_{2}$ to the ${ }^{3} \mathrm{P}$ and ${ }^{3} \mathrm{AP}$ respectively, while the third time is related with an unknown species $X$. To confirm such attribution, the effect of the addition of a quencher (2, 5-dimethyl-2, 4-hexadiene) on the kinetics at $440 \mathrm{~nm}$ has been tested with the resulting SternVolmer plot displayed in Figure $3 c$. As expected, $\tau_{1}$ and $\tau_{2}$ depend linearly on the quencher concentration which confirms the existence of both triplet states ${ }^{3} \mathrm{P}$ and ${ }^{3} \mathrm{AP}$ with a different quenching rate probably due to the difference in conformational arrangement of the two conformers. In contrast, the third species $X$ is insensitive to the diene addition which is an evidence for its singlet nature with biradical structure (oxygen quenching). We will reconsider this point just hereafter. At this point, comparing DTE and DMTPF, it is worth to notice a clear structural effect concerning the lifetimes of triplet states. The substitutions of terminal hydrogens by phenyl rings induce a clear enhancement of the lifetimes for the AP (25 vs $4 \mu \mathrm{s}$ ) species compared to $P$ species (2.6 vs $1.8 \mu \mathrm{s}$ ). Furthermore, in total consistency, the quenching rate constant are unaffected for $P$ species while the value is reduced by a factor 3 for the AP species. Those two results bring a strong evidence for a delocalization of the unpair electrons over the phenyl rings in the case of the AP species while such delocalization is lacking for the $\mathrm{P}$ species.

Origin of $\mathbf{X}$ species. We are now concerned by the identification of $X$ species. Such species have been reported in more or less extent for the different DTEs we studied in the past ${ }^{32-}$ ${ }^{34}$ but without noticeable photodegradation. In the case of DMTPF, we know that the sample has suffered some non-negligible photodegradation during transient experiment as proved by the presence of the by-product absorption band after the nanosecond measurements as shown in Figure S.4 and Figure S.5. Therefore, it seems reasonable to correlate the $\mathrm{X}$ species with a by-product precursor being in the singlet state with probable biradical structure. Following the admitted mechanism would be that the $X$ species is due to the re-excitation of the CF and the $X$ species would be a biradical species either in singlet or triplet states. By the way, among the two propositions emitted by Irie et al., (the 
direct precursors of the by-product in scheme 4 and scheme 5 in ref ${ }^{40}$ ),

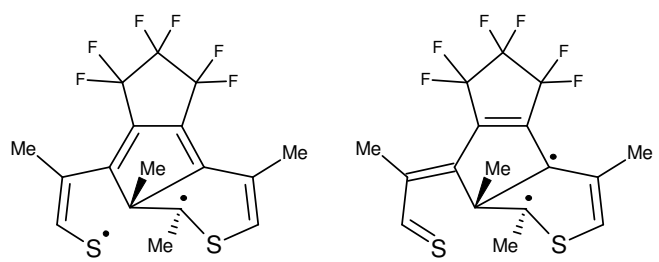

Scheme 2. Structure with two unpaired electrons.

we validate the structure with the two unpaired electrons far away compatible with a singlet nature. Such species would have a $13 \mu$ s lifetime.

At present time, this transient species responsible for the photodegradation is thought to originate from the CF excited state after UV irradiation. A second hypothesis is valuable as well involving the $\mathrm{P}$ conformer. Indeed, if we consider the relative contribution of triplet states species in the table 4, the results are instructive as well keeping in mind that the following discussion is qualitative. From NMR experiment, we know that the proportion of $\mathrm{P}$ conformer (see table 1 ) is much higher for DMTPF compared to DTE. Furthermore, it is worth to precise that molar extinction coefficient for the triplet states are expected to be in the same order of magnitude for both molecules (for DTE, spin density of ${ }^{3} \mathrm{AP}$ is not delocalized along lateral phenyls implying probable similar optical properties for DMTPF; see Figure S.24 of ref ${ }^{32}$ ) So, upon inspection of table 3 , the quite similar relative amplitudes for the decays (at around 15-20\%) suggest a similar ${ }^{3} \mathrm{AP}$ triplet population. In contrast, among the remaining ${ }^{3} \mathrm{P}$ population (75$80 \%$ ), one can notice that $50 \%$ of the $\mathrm{P}$ conformers are turned into $X$ species. Based on those results, we can emit a new hypothesis concerning the nature of the $X$ species: rather than originating from $\mathrm{CF}$ reexcitation, the by-product reported for diarylethene could come from the triplet of the $\mathrm{P}$ conformer of the OF. As an evidence, advanced CASSCF/CASPT2 calculations already performed for model DTEs ${ }^{29}$ are now desired to explore the pathways starting from either $\mathrm{CF}^{*}$ or from $\mathrm{P}^{*}$ species evolving trough the $X$ singlet biradical structure to finally giving birth to the by-product molecule. Just as challenging, the interconversion between AP and P at both singlet and triplet manifold have to be included.

Concerning the exact role of the triplet species in solid state DMTPF photochromism, although it exists constraints due to crystal lattice, we do not expect any photochromism from the triplet route ( $\left.{ }^{3} \mathrm{AP} \rightarrow \mathrm{CF}\right)$ because such a route is not observed in solution unlike the polyether bridged DTEs analogs. Indeed, the nanosecond transient signal acquired @ 550 nm CF maximum absorption (see Figure S.6) is a plateau for the long time, the height of this plateau being proportional to the photo induced CF. Such signal is insensitive to oxygen addition bringing evidence for a pure photocyclization route in the singlet manifold.

\section{Conclusion}

In this article, we investigated new insights into the ultrafast dynamics of the ring-closure reaction for DMTPF in solution by means of steady state, nanosecond and femtosecond absorption spectroscopy. The general mechanism is summarized in Figure 4. For the $\mathrm{P}$ conformer, a vibrational relaxation takes place at $\sim 300 \mathrm{fs}$ an expected ISC occurs (80 ps) to produce ${ }^{3} \mathrm{P}$. The latter relaxes to the ground state with a time constant $\sim 1.8 \mu \mathrm{s}$. Concerning the AP conformer, just after pump excitation a very rapid (90 fs) reaction channel for the ring closure was found. Then a triplet state is produced by the relaxed singlet state within $\sim 1.2 \mathrm{ps}$, the latter relaxes to the ground state within $4 \mu \mathrm{s}$. In addition, we reported the by-product formation for which a singlet precursor has a $13 \mu \mathrm{s}$ lifetime. The possible origin of this species is either re-excitation of CF species by UV light or related with the triplet state of the $\mathrm{P}$ conformer. These two routes are now under investigations in our laboratories combining ab initio calculations, HPLC and RPE measurements.

\section{Experimental Section}

DMTPF was synthesized following already published protocol. ${ }^{37}$ Chloroform solvents (spectroscopic grade, SigmaAldrich) were used as received. The stationary absorption spectra were measured with CARY 100 bio absorption spectrometer. ${ }^{1} \mathrm{H}$ NMR spectra were recorded on Bruker Avance-300 (300 MHz) in $\mathrm{CDCl}_{3}$ solvent. The photocyclization yields have already been published for $\mathrm{DTE}^{32}$ and similar measurements have been performed for DMTPF. For time-resolved measurements, adjusted concentrations were chosen around $10^{-4} \mathrm{~mol} \mathrm{dm}^{-3}$ to get an $O D$ around unity at the excitation wavelength. Our nanosecond transient absorption spectroscopy setup has been described elsewhere. ${ }^{41}$ Briefly, the third harmonic of a nanosecond Nd:YAG laser is used to pump a frequency doubled OPO laser tuned at $290 \mathrm{~nm}$. 1mJ, $5 \mathrm{~ns}, 290 \mathrm{~nm}$ pulses were used as excitation light and a pulsed Xe lamp was utilized as the probe light. Transient absorption spectra were obtained from the transient absorption decays recorded at various wavelengths by sampling the absorbance changes for different given delay-times. Femtosecond time-resolved experiments were performed using a pump-probe spectrometer ${ }^{42,43}$ based on Ti:sapphire laser system (Coherent Mira-900-D oscillator and Libra-S regenerative 
amplifier) delivering $800 \mathrm{~nm}, 1 \mathrm{~mJ}$ and $90 \mathrm{fs}$ pulses with a repetition rate of $1 \mathrm{kHz}$. The pump pulses adjusted at $320 \mathrm{~nm}$ were generated by frequency quadrupling the output of a Quantronix Palitra OPA pumped at $800 \mathrm{~nm}$ and the energy at the sample was about $2 \mu \mathrm{J}\left(0.2 \mathrm{~mJ} \mathrm{~cm}^{-2}\right)$. Note that, we decided to excite the molecule far from the absorption peak which is localized near $270 \mathrm{~nm}$ to avoid short-time signal coming from the solvent. The probe pulses were obtained by focusing $1 \mu \mathrm{J}, 800 \mathrm{~nm}$ pulses into a $1 \mathrm{~mm} \mathrm{CaF} 2$ plate to generate a white light continuum. The pump-probe polarization configuration was set at the magic angle $\left(54.7^{\circ}\right)$. Transient absorbance was obtained by comparing signal and reference spectra with and without pump pulses for different delay times. The delay time between the pump and probe was varied up to $0.5 \mathrm{~ns}$ using an optical delay line. Sample solutions were circulated in a cell equipped with $200 \mu \mathrm{m}$ thick $\mathrm{CaF}_{2}$ entrance window and having $2 \mathrm{~mm}$ optical path length. The sample solution was circulated during measurements and was irradiated by $\mathrm{CW}$ Xe lamp visible light to prevent the accumulation of CF. In this configuration, for $320 \mathrm{~nm}$ excitation, the instrumental response function determined by fitting the Stimulated Raman transient spectra of acetonitrile was determined to be $180 \mathrm{fs}$ (see Figure S.7.). All the transient spectra presented in this paper are GVD corrected according to the typical extrapolation method ${ }^{44,45}$ (the temporal chirp over the white-light $350-800 \mathrm{~nm}$ range was about $400 \mathrm{fs}$ ). The characteristic times deduced from kinetics are obtained by fitting the data with the result of a multi-exponential function convolved with a Gaussian pulse mimicking the pumpprobe cross-correlation function (FWHM at $180 \mathrm{fs}$ ).

\section{Acknowledgements}

Chevreul Institute (FR 2638), Ministère de l'Enseignement Supérieur et de la Recherche, Région NordPas de Calais and FEDER are acknowledged for supporting and funding this work.

This article is dedicated to the memory of Dr. Olivier Poizat, CNRS researcher at LASIR laboratory, who passed away much too soon. Olivier Poizat led the "photochemistry" team at LASIR for many years with great involvement, kindness and modesty. He was able to unite energies around numerous fundamental research projects dealing with photochemistry, photophysics and spectroscopy. He was at the origin of many research themes and of the development of time-resolved spectroscopy experiments in the laboratory. Throughout his career, he has participated in the training of many $\mathrm{PhD}$ students, post-doctorants and junior researchers. The authors of this paper are infinitely grateful to him for his unfailing support in the development of researches on the elucidation of reaction mechanisms of photochromic molecules and for the many fruitful discussions they had with him on this subject and many others. Rest in peace Olivier.

Keywords: Photochromism, Photophysics, Photochemistry, Transient Absorption, Ultrafast dynamics. 
(1) Crano, J. C.; Guglielmetti, R. J. Organic Photochromic and Thermochromic Compounds; J.C Crano, R. J. G., Series Ed.; Plenum: New York, 1999; Vol. 1,2.

(2) Feringa, B. L. Molecular Switches; Wiley-VCH: Darmstadt, 2001.

(3) Bouas-Laurent, H.; Durr, H. Organic Photochromism (IUPAC Technical Report); Durr, H., BouasLaurent, H., Series Eds.; Photochromism: Molecules and Systems; Elsevier Science Bv: Amsterdam, 2003. https://doi.org/10.1016/b978-044451322-9/50004-x.

(4) Tian, H.; Zhang, J. Photochromic Materials: Preparation, Properties and Applications; Photochromic Materials: Preparation, Properties and Applications; 2016. https://doi.org/10.1002/9783527683734.

(5) Pu, S. Z.; Yang, T. S.; Yao, B. L.; Wang, Y. L.; Lei, M.; Xu, J. K. Photochromic Diarylethene for Polarization Holographic Optical Recording. Mater. Lett. 2007, 61 (3), 855-859.

(6) Andréasson, J.; Pischel, U. Storage and Processing of Information Using Molecules: The All-Photonic Approach with Simple and Multi-Photochromic Switches. Isr. J. Chem. 2013, $53 \quad$ (5), 236-246. https://doi.org/10.1002/ijch.201300014.

(7) Avella-Oliver, M.; Morais, S.; Puchades, R.; Maquieira, A. Towards Photochromic and Thermochromic Biosensing. TrAC - Trends Anal. Chem. 2016, 79, 37-45. https://doi.org/10.1016/j.trac.2015.11.021.

(8) Cheng, H.; Yoon, J.; Tian, H. Recent Advances in the Use of Photochromic Dyes for Photocontrol in Biomedicine. Coord. Chem. Rev. 2018, 372, 66-84. https://doi.org/10.1016/j.ccr.2018.06.003.

(9) Metivier, R.; Amengual, R.; Leray, I.; Michelet, V.; Genet, J. P. Novel Fluorophores: Efficient Synthesis and Photophysical Properties. Org. Lett. 2004, 6 (5), 739-742.

(10) Metivier, R.; Leray, I.; Valeur, B. A Highly Sensitive and Selective Fluorescent Molecular Sensor for $\mathrm{Pb}(\mathrm{II})$ Based on a Calix 4 Arene Bearing Four Dansyl Groups. Chem. Commun. 2003, No. 8, 996-997.

(11) Goulet-Hanssens, A.; Eisenreich, F.; Hecht, S. Enlightening Materials with Photoswitches. Adv. Mater. 2020. https://doi.org/10.1002/adma.201905966.

(12) Russew, M. M.; Hecht, S. Photoswitches: From Molecules to Materials. Adv. Mater. 22 (31), 3348-3360. https://doi.org/10.1002/adma.200904102.

(13) Irie, M. Diarylethenes for Memories and Switches. Chem. Rev. 2000, 100 (5), 1685-1716.

(14) Irie, M.; Fukaminato, T.; Matsuda, K.; Kobatake, S. Photochromism of Diarylethene Molecules and Crystals: Memories, Switches, and Actuators. Chem. Rev. 2014, 114 (24), 12174-12277. https://doi.org/10.1021/cr500249p.
(15) Herder, M.; Schmidt, B. M.; Grubert, L.; Paetzel, M.; Schwarz, J.; Hecht, S. Improving the Fatigue Resistance of Diarylethene Switches. J. Am. Chem. Soc. 2015, 137 (7), 2738-2747. https://doi.org/10.1021/ja513027s.

(16) Uchida, K.; Tsuchida, E.; Aoi, Y.; Nakamura, S.; Irie, M. Substitution Effect on the Coloration Quantum Yield of a Photochromic Bisbenzothienylethene. Chem. Lett. 1999, No. 1, 63-64.

(17) Morimitsu, K.; Kobatake, S.; Irie, M. Large Geometrical Structure Changes of Photochromic Diarylethenes upon Photoirradiation. Tetrahedron Lett. 2004, 45 (6), 11551158. https://doi.org/10.1016/j.tetlet.2003.12.005.

(18) Takeshita, M.; Nagai, M.; Yamato, T. A Photochromic Thiophenophan-1-Ene. Chem. Commun. 2003, No. 13, 1496-1497. https://doi.org/10.1039/b303916a.

(19) Takeshita, M.; Jin-nouchi, H.; Ishikawa, J. Syntheses and Photochromic Properties of Metacyclothiophenophan-1Enes. Chem. Lett. 2009, 38 (10), 982-983. https://doi.org/10.1246/cl.2009.982.

(20) Takeshita, M.; Yamato, T. Enantioselective Photochromic Reaction of a 2.2 Metacyclophan-1-Ene. Angew. Chem.Int. Ed. 2002, $41 \quad$ (12), 2156-2157. https://doi.org/10.1002/15213773(20020617)41:12<2156::aid-anie2156>3.0.co;2-0.

(21) Fukumoto, S.; Nakashima, T.; Kawai, T. Intramolecular Hydrogen Bonding in a Triangular Dithiazolyl-Azaindole for Efficient Photoreactivity in Polar and Nonpolar Solvents. Eur. J. Org. Chem. 2011, No. 26, 5047-5053. https://doi.org/10.1002/ejoc.201100676.

(22) Ishibashi, Y.; Okuno, K.; Ota, C.; Umesato, T.; Katayama, T.; Murakami, M.; Kobatake, S.; Irie, M.; Miyasaka, H. Multiphoton-Gated Cycloreversion Reactions of Photochromic Diarylethene Derivatives with Low Reaction Yields upon One-Photon Visible Excitation. Photochem. Photobiol. Sci. 2010, 9 (2), 172-180. https://doi.org/10.1039/b9pp00116f.

(23) Ishibashi, Y.; Mukaida, M.; Falkenstrom, M.; Miyasaka, H.; Kobatake, S.; Irie, M. One- and Multi-Photon Cycloreversion Reaction Dynamics of Diarylethene Derivative with Asymmetrical Structure, as Revealed by Ultrafast Laser Spectroscopy. Phys. Chem. Chem. Phys. 2009, $11 \quad$ (15), 2640-2648. https://doi.org/10.1039/b818591c.

(24) Kumpulainen, T.; Lang, B.; Rosspeintner, A.; Vauthey, E. Ultrafast Elementary Photochemical Processes of Organic Molecules in Liquid Solution. Chem. Rev. 2017, 117 (16), 10826-10939. https://doi.org/10.1021/acs.chemrev.6b00491.

(25) Sotome, H.; Kitagawa, D.; Nakahama, T.; Ito, S.; Kobatake, S.; Irie, M.; Miyasaka, H. Cyclization Reaction Dynamics of 
an Inverse Type Diarylethene Derivative as Revealed by Time-Resolved Absorption and Fluorescence Spectroscopies. Phys. Chem. Chem. Phys. 2019, 21 (17), 8623-8632. https://doi.org/10.1039/c8cp07393g.

(26) Jarota, A.; Pastorczak, E.; Abramczyk, H. A Deeper Look into the Photocycloreversion of a Yellow Diarylethene Photoswitch: Why Is It so Fast? Phys. Chem. Chem. Phys. 2020, $22 \quad$ (10), 5408-5412. https://doi.org/10.1039/c9cp05452a.

(27) Seo, K.; Eom, I.; Shim, S.; Kim, C. H.; Joo, T. Ring Closure Reaction Pathway of a Diarylethene in Solution Using Femtosecond Time-Resolved Fluorescence Spectra. Bull. Korean Chem. Soc. 2019, 40 (4), 352-358. https://doi.org/10.1002/bkcs.11689.

(28) Nakamura, S.; Yokojima, S.; Uchida, K.; Tsujioka, T.; Goldberg, A.; Murakami, A.; Shinoda, K.; Mikami, M.; Kobayashi, T.; Kobatake, S.; Matsuda, K.; Irie, M. Theoretical Investigation on Photochromic Diarylethene: A Short Review. J. Photochem. Photobiol. Chem. 2008, 200 (1), 10-18. https://doi.org/10.1016/j.jphotochem.2008.05.005.

(29) Perrier, A.; Aloise, S.; Olivucci, M.; Jacquemin, D. Inverse versus Normal Dithienylethenes: Computational Investigation of the Photocyclization Reaction. J. Phys. Chem. Lett. 2013, 4 (13), 2190-2196. https://doi.org/10.1021/jz401009b.

(30) Boggio-Pasqua, M.; Ravaglia, M.; Bearpark, M. J.; Garavelli, M.; Robb, M. A. Can Diarylethene Photochromism Be Explained by a Reaction Path Alone? A CASSCF Study with Model MMVB Dynamics. J. Phys. Chem. J Phys Chem A 2003, 107 (50), 11139-11152. https://doi.org/10.1021/jp036862e.

(31) Aloise, S.; Sliwa, M.; Pawlowska, Z.; Rehault, J.; Dubois, J.; Poizat, O.; Buntinx, G.; Perrier, A.; Maurel, F.; Yamaguchi, S.; Takeshita, M. Bridged Photochromic Diarylethenes Investigated by Ultrafast Absorption Spectroscopy: Evidence for Two Distinct Photocyclization Pathways. J Am Chem Soc 2010, 132 (21), 7379-7390.

(32) Hamdi, I.; Buntinx, G.; Perrier, A.; Devos, O.; Jaidane, N.; Delbaere, S.; Tiwari, A. K.; Dubois, J.; Takeshita, M.; Wada, Y.; Aloise, S. New Insights into the Photoswitching Mechanisms of Normal Dithienylethenes. Phys. Chem. Chem. Phys. 2016. https://doi.org/10.1039/C6CP03471C.

(33) Hamdi, I.; Buntinx, G.; Poizat, O.; Delbaere, S.; Perrier, A.; Yamashita, R.; Muraoka, K.; Takeshita, M.; Aloïse, S. Unraveling Ultrafast Dynamics of the Photoswitchable Bridged Dithienylethenes under Structural Constraints. Phys. Chem. Chem. Phys. 2019, 21 (12), 6407-6414. https://doi.org/10.1039/C8CP07100D.
(34) Hamdi, I.; Buntinx, G.; Poizat, O.; Perrier, A.; Le Bras, L.; Delbaere, S.; Barrau, S.; Louati, M.; Takeshita, M.; Tokushige, K.; Takao, M.; Aloïse, S. Excited-State Dynamics of Dithienylethenes Functionalized for SelfSupramolecular Assembly. J. Phys. Chem. A 2018, 122 (14), 3572-3582. https://doi.org/10.1021/acs.jpca.7b10767.

(35) Irie, M. Photochromic Diarylethenes for Photonic Devices. Pure Appl. Chem. 1996, 68 (7), 1367-1371.

(36) Kobatake, S.; Muto, H.; Irie, M. Excited State Energy Migration and Photochromic Reaction in 1,2-Bis(2,4Dimethyl-3-Thienyl)Perfluorocyclopentene Single Crystal. Chem. Lett. 2005, $35 \quad$ (1), 102-103. https://doi.org/10.1246/cl.2006.102.

(37) Irie, M.; Sakemura, K.; Okinaka, M.; Uchida, K. Photochromism of Dithienylethenes with ElectronDonating Substituents. J. Org. Chem. 1995, 60 (25), 83058309.

(38) Irie, M.; Eriguchi, T.; Takada, T.; Uchida, K. Photochromism of Diarylethenes Having Thiophene Oligomers as the Aryl Groups. Tetrahedron 1997, 53 (36), 12263-12271.

(39) Higashiguchi, K.; Matsuda, K.; Yamada, T.; Kawai, T.; Irie, M. Fatigue Mechanism of Photochromic 1,2-Bis(3Thienyl)Perfluorocyclopentene. Chem. Lett. 2000, 29 (12), 1358-1359. https://doi.org/10.1246/cl.2000.1358.

(40) Higashiguchi, K.; Matsuda, K.; Kobatake, S.; Yamada, T.; Kawai, T.; Irie, M. Fatigue Mechanism of Photochromic 1,2-Bis(2,5-Dimethyl-3-Thienyl)Perfluorocyclopentene.

Bull. Chem. Soc. Jpn. 2000, 73 (10), 2389-2394. https://doi.org/10.1246/bcsj.73.2389.

(41) Buntinx, G.; Poizat, O.; Leygue, N. TRANSIENT ABSORPTION AND RESONANCE RAMAN INVESTIGATION OF THE PHOTOCHEMICAL REACTIVITY OF 2,2'-BIPYRIMIDINE IN SOLUTION. J. Phys. Chem. 1995, 99 (8), 2343-2352. https://doi.org/10.1021/j100008a016.

(42) Buntinx, G.; Naskrecki, R.; Poizat, O. Subpicosecond Transient Absorption Analysis of the Photophysics of 2,2'Bipyridine and 4,4'-Bipyridine in Solution. J. Phys. Chem. 1996, $\quad 100 \quad(50), \quad 19380-19388$ https://doi.org/10.1021/jp960900v.

(43) Moine, B.; Rehault, J.; Aloise, S.; Micheau, J. C.; Moustrou, C.; Samat, A.; Poizat, O.; Buntinx, G. Transient Absorption Studies of the Photochromic Behavior of 3H-Naphtho[2,1b]Pyrans Linked to Thiophene Oligomers via an Acetylenic Junction. J. Phys. Chem. A 2008, 112 (21), 4719-4726. https://doi.org/10.1024/jp711865j

(44) Nakayama, T.; Amijima, Y.; Ibuki, K.; Hamanoue, K. Construction of a Subpicosecond Double-Beam Laser 
Photolysis System Utilizing a Femtosecond Ti:Sapphire Amplifiers (a Regenerative Amplifier and Two Double Passed Linear Amplifiers), and Measurements of the Transient Absorption Spectra by a Pump-Probe Method. Rev Sci Instrum 1997, 68 (12), 4364-4371.

(45) Ziolek, M.; Lorenc, M.; Naskrecki, R. Determination of the Temporal Response Function in Femtosecond PumpProbe Systems. Appl. Phys. B-Lasers Opt. 2001, 72 (7), 843-847. 